УДК 796.015.132

DOI: 10.35750/2071-8284-2019-3-197-203

\title{
А.А. Третьяков
}

кандидат педагогических наук, доцент

Белгородский юридчческий институт МВД России И.Д. Путилина

Российская Федеращия, 308024, Белгород, ул. Горького, 71

ORCID: 0000-0001-7498-6675.E-mail:delphin87@inbox.ru

А.И. Ткаченко

кандидат педагогических наук, доцент

Белгородский юридический институт МВД России имени И.Д. Путилина

Российская Федерация, 308024, г. Белгород, ул. Горького, 71

ORCID: 0000-0003-0227-6118. E-mail: Tkachenkoai1@yandex.ru

\section{В.В. Дрогомерецкий}

кандидат педагогических наук, доцент

Белгородский государственный национальный исследовательский университет

Российская Федераиия, 308015, г. Белгород, ул. Победы, 85

ORCID: 0000-0002-4749-2853.E-mail:drogomeretskiy@bsu.edu.ru

\section{Обучение курсантов основам прикладного плавания}

Аннотация: В работе проводится обоснование решения проблемы обучения основам прикладного плавания курсантов образовательных организаций МВД России. Необходимость обучения данным умениям курсантов высока. Многие обучающиеся в образовательных организациях МВД не знают, как оказывать помощь и противодействовать преступнику в водной среде. Несмотря на это, будущие сотрудники полиции во время исполнения служебных обязанностей обязаны оказать помощь при необходимости, а в рамках предупреждения преступности, соответственно, вести преследование, оказывать противодействие и задерживать в водной среде правонарушителя. Данные обстоятельства определили необходимость разработки методики обучения основам прикладного плавания курсантов образовательных организаций МВД России. Предполагалось провести анализ уровня подготовленности курсантов в вопросах знания основ прикладного плавания. Разработать программу обучения курсантов основам прикладного плавания и проверить ее эффективность. В процессе проведения исследования использовались методы педагогические, практические и математико-статистические. В ходе проведения исследования было установлено, что предложенная программа практических занятий и методика по обучению основам прикладного плавания является эффективной. На это указывают экспериментальные данные, полученные в результате тестирования курсантов. Данный факт позволяет рекомендовать экспериментальную методику к использованию в учебном процессе курсантов.

Ключевые слова: физическая подготовка, курсанты, прикладное плавание, спасение утопающих, методика, умения, учебный процесс.

Для цитирования: Третьяков А.А., Ткаченко А.И., Дрогомерецкий В.В. Обучение курсантов основам прикладного плавания // Вестник Санкт-Петербургского университета МВД России. - 2019. № 3 (83). - C. 197-203. DOI: 10.35750/2071-8284-2019-3-197-203.

Andrey A. Tretyakov

Cand. Sci. (Ped.), Docent

I.D. Putilin Belgorod Law Institute of the MIA of Russia

71, Gorkyi str., Belgorod, 308024, Russian Federation

ORCID: 0000-0001-7498-6675. E-mail: delphin87@inbox.ru 


\author{
Alexey I. Tkachenko \\ Cand. Sci. (Ped.), Docent \\ I.D. Putilin Belgorod Law Institute of the MIA of Russia \\ 71, Gorkyi str., Belgorod, 308024, Russian Federation \\ ORCID: 0000-0003-0227-6118 \\ E-mail:Tkachenkoai1@yandex.ru \\ Vladimir V. Drogomeretskiy \\ Cand. Sci. (Ped.), Docent \\ I.D. Putilin Belgorod Law Institute of the MIA of Russia \\ 71, Gorkyi str., Belgorod, 308024, Russian Federation \\ ORCID: 0000-0002-4749-2853 \\ E-mail:drogomeretskiy@bsu.edu.ru
}

\title{
Learning the basics of applied swimming cadets
}

Annotation: The paper presents the rationale for solving the problem of teaching the basics of applied swimming cadets of educational institutions of the Ministry of internal Affairs. The need for training these skills of cadets is high. Many students in the educational organizations of the Ministry of internal Affairs do not know how to assist and counteract the criminal in the water environment. Despite this, the future police during execution of official duties, the duty to assist, where appropriate, and within the framework of crime prevention, respectively, to the persecution, to oppose and delay in the aquatic environment of the offender. These circumstances determined the need to develop methods of teaching the basics of applied swimming cadets of educational institutions of the Ministry of internal Affairs. It was supposed to carry out the analysis of level of readiness of cadets in questions of knowledge of bases of applied swimming. To develop a program of training students in the basics of applied swimming and test its effectiveness. In the course of the study, pedagogical, practical, mathematical and statistical methods were used. In the course of the study it was found that the proposed program of practical training and methodology for teaching the basics of applied swimming is effective. This is indicated by the experimental data obtained as a result of testing of cadets. This fact allows us to recommend an experimental technique for use in the educational process of students.

Keywords: physical training, cadets, applied swimming, rescue of drowning, technique, skills, educational process.

For citation: Tretyakov A.A., Tkachenko A.I., Drogomeretskiy V.V. Learning the basics of applied swimming cadets // Vestnik of St. Petersburg University of the Ministry of Internal Affairs of Russia. - 2019. № 3 (83). - P. 197-203. DOI: 10.35750/2071-8284-2019-3-197-203.

Введение. Профессиональная деятельность в различных отраслях с каждым годом становится все более узконаправленной. Действия специалистов требуют владения умениями и навыками, специфичными для определённой отрасли [1]. Однако в обществе существуют профессии, которые обязывают их обладателей владеть большим спектром умений и навыков из различных отраслей деятельности [2]. Так, сотрудник полиции должен хорошо знать законодательство и умело им руководствоваться; владеть высоким уровнем физической и огневой подготовленности, чтобы суметь оказать противодействие преступникам, предупредить действия правонарушителей, вступить в противоборство для пресечения противоправных действий и многое другое. Также сотрудник полиции обязан уметь оказывать доврачебную помощь пострадавшим в любых условиях. Перечисленными выше умениями и навыками перечень не ограничивается. Но необходимо остановиться на навыках оказания помощи и противодействия в среде, которая нас окружает.

В летний период увеличивается количество мест отдыха у водоемов [3]. Данные места входят в область патрулирования полицейских. На водные просторы выходят легкомоторные лодки, плоты, баржи, пассажирские и грузовые суда и т.д., что входит в сферу деятельности транспортной полиции [4]. При пресечении противоправных действий преступники могут оказаться в воде, где им необходимо будет дать отпор, 
задержать и сопроводить к месту дислокации полицейского подразделения. Всеми перечисленными действиями важно владеть каждому сотруднику полиции. Данные действия рассматриваются в отдельной отрасли - прикладном плавании [5].

За время обучения в образовательных организациях МВД у курсантов должна быть возможность овладеть основами прикладного плавания, поскольку данные умения и навыки позволят сохранить жизнь как самому сотруднику, так и пострадавшему или правонарушителю. Приказ МВД России от 1 июля 2017 г. № 450 «Об утверждении Наставления по организации физической подготовки в органах внутренних дел Российской Федерации» предусматривает плавательную подготовку обучающихся и сотрудников полиции [6]. К сожалению, ни в одной из образовательных организаций МВД России не проводятся занятия по основам прикладного плавания [7].

Из вышесказанного возникает проблема, которая заключается в необходимости обучения будущих сотрудников полиции умениям и навыкам оказания помощи и противодействия в водной среде и в отсутствии проверенных путей и способов обучения курсантов основам прикладного плавания.

Организация и методы исследования. Исследование проводилось в три этапа. На первом этапе анализировалась научно-методическая литература по проблеме исследования. Был проведён опрос среди курсантов с целью определения исходного уровня знаний о прикладном плавании. Педагогическое исследование проводилось на втором этапе исследования. Оно предполагало апробацию экспериментальной методики обучения курсантов основам прикладного плавания. На заключительном этапе обрабатывались данные, полученные в ходе эксперимента. Формировались выводы и разрабатывались практические рекомендации по использованию методики обучения курсантов основам прикладного плавания.

Для оценки исходного уровня и представлений курсантов о прикладном плавании в рамках исследования проводился опрос (анкетирование). Анкета была разработана и апробирована на кафедре физической подготовки БелЮИ МВД России имени И.Д. Путилина и на кафедре спортивных дисциплин НИУ «БелГУ». В анкету были включены 20 вопросов для оценки плавательной подготовленности, представлений о передвижении в воде, оказания помощи пострадавшему в воде, противодействию пре- ступнику в водной среде и вопросы о необходимости обучения основам прикладного плавания. В опросе приняли участие курсанты 1-3-х курсов. В общей сложности было опрошено более 150 курсантов.

Педагогический эксперимент проводился в 2019 году в течение четырёх месяцев. Эксперимент носил характер констатирующего. Занятия проводились во внеучебное время, два раза в неделю. Длительность занятия - 90 минут, из них 45 минут в спортивном зале, а 45 минут - в бассейне. В эксперименте приняли участие 14 курсантов (юноши) третьего года обучения. Все испытуемые хорошо владели навыками плавания.

Уровень плавательной подготовленности оценивался преодолением 50-метровой дистанции стилем «брасс» и такой же - стилем «кроль». Фиксировалось время проплывания дистанций. Для оценки умений прикладной направленности был предложен ряд тестов. Данные тесты были заимствованы из программы дисциплины «Теория и методика обучения плаванию» для бакалавров факультета физической культуры НИУ «БелГУ».

«Плавание в форме» - фиксировалось время проплывания 50 метров в полевой форме без обуви. «Ныряние в длину» - фиксировалось расстояние, преодолеваемое под водой. «Ныряние в глубину» - необходимо было достать предмет (хоккейная шайба) с глубины 6 метров. Ныряние проводилось с поверхности воды. Глубина ограничивалась ванной бассейна. «Транспортировка пострадавшего» - фиксировалось время транспортировки напарника на 50 метров. Можно было использовать различные варианты транспортировки. «Освобождение от захвата» - фиксировалось время с момента захвата напарником, выполняющего роль нападавшего, до момента освобождения от захвата и перехода в положение транспортировки в воде. Захват определялся педагогом перед схваткой.

Для обработки полученных данных использовались методы математической статистики.

Результать исследования и их обсуждение. Проведённый опрос среди курсантов БелЮИ МВД России имени И.Д. Путилина показал, что представление о прикладном плавании у обучающихся отсутствует. Большая часть опрошенных не знает, в чем разница между прикладным и спортивным плаванием. Также курсанты не знают способы, которыми можно преодолевать дистанции на воде. Проведение опроса выявило, что треть курсантов обладают низкой плавательной подготовленностью - они слабо держатся на воде и не могут передвигаться 


\section{Экспериментальная программа обучения курсантов основам прикладного плавания}

\begin{tabular}{|c|c|c|c|}
\hline № & $\begin{array}{c}\text { Наименование } \\
\text { раздела }\end{array}$ & Содержание раздела & $\begin{array}{l}\text { Ko.I-BO } \\
\text { yacoB* }\end{array}$ \\
\hline 1 & Вводные занятия & $\begin{array}{c}\text { Занятия предусматривают знакомство с терминологией, со } \\
\text { спортивными способами плавания, определение дистанций } \\
\text { пропывания }\end{array}$ & 4 \\
\hline 2 & $\begin{array}{l}\text { Приклалиые } \\
\text { способы плавания }\end{array}$ & $\begin{array}{l}\text { Обучение прнкладным способам плавания (брасе на спине, на боку, } \\
\text { смепанные способы) }\end{array}$ & 10 \\
\hline 3 & $\begin{array}{l}\text { Транспортировка } \\
\text { предметов }\end{array}$ & Обучение транспортировке предметов над водой, в воде, под водой & 6 \\
\hline 4 & $\begin{array}{l}\text { Транспортировка } \\
\text { человека }\end{array}$ & $\begin{array}{c}\text { Обучение транспортировке уставшего пловца, пострадавшего без } \\
\text { сознания-в сознании, буйного }\end{array}$ & 14 \\
\hline 5 & $\begin{array}{l}\text { Нырянис в длнну, } \\
\text { прыжки }\end{array}$ & $\begin{array}{c}\text { Обучение прыжкам ногами вперед, руками вперёд с борта и } \\
\text { стартовой тумбы; обучение задержке дыхания, передвижению вод } \\
\text { водой различными способами }\end{array}$ & 8 \\
\hline 6 & $\begin{array}{l}\text { Ныряние в } \\
\text { глубнну, прыжки }\end{array}$ & $\begin{array}{c}\text { Обучение прыжкам ногами вперёд, руками вперёд с вышки (1 и } 3 \\
\text { метра); обучение задержке дыхания, «продувке» во время } \\
\text { погружегия, пыряпию в глубипу различпыми способами }\end{array}$ & 8 \\
\hline 7 & $\begin{array}{l}\text { Приёмы борьбы и } \\
\text { освобождения от } \\
\text { захватов }\end{array}$ & $\begin{array}{c}\text { Обучение приёмам борьбы в воде, атакующие и контратакующие; } \\
\text { освобождение от захватов, обхватов }\end{array}$ & 12 \\
\hline 8 & $\begin{array}{l}\text { Довратебная } \\
\text { помощь }\end{array}$ & $\begin{array}{c}\text { Обучение подъёму ео дна пострадавшего, подьём на сушу в } \\
\text { различных услювиях, подготовнтельным действиям при извлечении } \\
\text { из воды, доврачебным действиям при угоплении }\end{array}$ & 12 \\
\hline \multicolumn{3}{|r|}{ Итого } & 64 \\
\hline
\end{tabular}

на короткие расстояния в нужном направлении. К сожалению, в период дальнейшей службы эти курсанты не смогут во время выполнения оперативно-служебных, служебно-боевых задач, очутившись в водной среде, оказать противодействие правонарушителю и помочь пострадавшему.

В следующем блоке вопросов оценивались знания приёмов борьбы и транспортировки в водной среде. Большая часть опрошенных не знает, как вести борьбу с правонарушителем в водной среде, какие приемы использовать в процессе освобождения от захватов и для предупреждения атакующих действий. Отсутствуют представления о способах транспортировки и извлечения из воды пострадавших.

Отвечая на вопросы о доврачебной помощи, курсанты проявили высокий уровень знаний. Это можно связать с изучением в образовательном процессе дисциплины «Первая доврачебная помощь».
В заключительном блоке вопросов курсанты отметили важность владения умениями и навыками плавательной подготовленности и прикладной направленности плавания. Большой интерес вызвали предложения по обучению основам прикладного плавания курсантов во время учёбы в образовательной организации МВД России.

По итогам проведённого опроса и анализа литературных источников было предложено организовать обучение основам прикладного плавания курсантов. Курсанты, принявшие участие в исследовании, умели плавать достаточно хорошо. Вопрос, касающийся обучения основам прикладного плавания курсантов, не умеющих плавать, должен рассматриваться в отдельном исследовании, так как действия, связнные с оказанием помощи на воде, требуют хорошей плавательной подготовленности.

Перед обучением основам прикладного плавания было предложено провести два озна- 


\section{Оценка уровня плавательной подготовленности}

\begin{tabular}{|c|c|c|}
\hline \multirow{2}{*}{ Этапы } & \multicolumn{2}{|c|}{ Тесты } \\
\cline { 2 - 3 } & 50 м $\mathrm{B} / \mathrm{c}, \mathrm{ce \kappa}$ & 50 м брасс, $\mathrm{ce \kappa}$ \\
\hline До & $41,2 \pm 4,05$ & $53,1 \pm 5,13$ \\
\hline После & $35,3 \pm 3,43$ & $45,6 \pm 4,49$ \\
\hline$P$ & + & + \\
\hline
\end{tabular}

комительных занятия с элементами спортивного плавания. В лучшем случае к обучению необходимо допускать курсантов, владеющих навыком плавания не ниже юношеского разряда.

Последовательность обучения основам прикладного плавания должна проходить по общему принципу «от простого к сложному». Обучение необходимо проводить в следующей последовательности: обучение прикладным способам плавания, плавание в одежде или снаряжении, обучение приемам борьбы в воде, оказание помощи на суше, на воде (на мелком месте, на глубокой воде с манекеном, на глубокой воде с партнером), доврачебная помощь. Экспериментальная программа обучения представлена в таблице 1 ( ${ }^{*}$ в таблице указаны академические часы).

Педагогический эксперимент проводился в течение 4 месяцев. Занятия проводились во внеучебное время, два раза в неделю. Длительность занятия 90 минут. Из них 45 минут занятия проводились в спортивном зале, а 45 минут - в бассейне. База БелЮИ МВД России имени И.Д. Путилина не располагает бассейном, поэтому занятия проводились в бассейне УСК С. Хоркиной НИУ «БелГУ».

На первом занятии определялся исходный уровень плавательной подготовленности участников эксперимента. Полученные результаты в группе указывают на то, что юноши находятся на одном уровне плавательной подготовленно- сти. Результаты в кроле на груди заметно лучше, чем в плавании брассом (табл. 2).

По окончании эксперимента было проведено повторное тестирование плавательной подготовленности. За время проведения эксперимента результаты на данных дистанциях улучшились, что указывает на рост плавательной подготовленности. Большая динамика наблюдается в плавании брассом, что можно связать с большим количеством заданий, выполняющихся способом «брасс» или с элементами брасса. В данном исследовании брасс имеет большую прикладную значимость, чем кроль,.

Проведение занятий в спортивном зале позволило создать представление у курсантов об умениях, которыми они должны пользоваться в воде. Так, на суше разбиралась техника прикладных способов плавания. Приёмы борьбы подробно разбирались на занятиях в парах в зале. Также большое внимание уделялось доврачебной помощи, технике и тактике оказания помощи на воде.

Оценка владения основами прикладного плавания также проводилась в начале эксперимента и по его окончании (табл. 3). На первом тестировании курсанты испытывали трудности при выполнении тестовых заданий. Действия носили интуитивный характер и в большей степени поддерживались хорошей физической подготовкой. Несмотря на это, при выполнении

Таблица 3

Определение уровня развития умений в прикладном плавании

\begin{tabular}{|c|c|c|c|c|c|}
\hline \multirow[b]{2}{*}{ Этапы } & \multicolumn{5}{|c|}{ Тесты } \\
\hline & $\begin{array}{c}50 \text { м брасс } \\
\text { « форме», } \\
\text { сек }\end{array}$ & $\left|\begin{array}{l}\text { Ньюряние } \\
\text { в длину, м }\end{array}\right|$ & $\begin{array}{l}\text { Ньгряние в } \\
\text { глубину, } м\end{array}$ & $\begin{array}{c}\text { Транспортировка, } \\
\text { сек }\end{array}$ & $\begin{array}{c}\text { Освобожсдение } \\
\text { от захвата, } \\
\text { сек }\end{array}$ \\
\hline До & $142,5 \pm 23,1$ & $12,1 \pm 1,2$ & - & $138,7 \pm 18,1$ & $9,3 \pm 1,3$ \\
\hline После & $67,7 \pm 5,2$ & $25,4 \pm 3,1$ & 6 & $89,5 \pm 11,3$ & $4,5 \pm 1,0$ \\
\hline$P$ & + & + & + & + & + \\
\hline
\end{tabular}


ныряния в длину курсанты показали невысокие результаты, а с тестом «ныряние в глубину» не справился никто. При выполнении «освобождения от захвата» все курсанты использовали приёмы, разученные на занятиях по физической подготовке.

По окончании эксперимента было проведено повторное тестирование, которое выявило положительную динамику в формировании умений и навыков прикладного плавания. Peзультаты в «плавании в форме» улучшились в два раза. При нырянии в длину результат у курсантов превысил 25 метров. Все юноши выполнили тест «ныряние в глубину», достигнув дна бассейна в 6 метров. Время транспортировки пострадавшего улучшилось. Освобождение от захвата курсанты выполняли вдвое быстрее, чем ранее.

Заключение. В ходе проведения исследования было установлено, что предложенная программа практических занятий по обучению основам прикладного плавания является эффективной. На это указывают экспериментальные данные, полученные в результате тестирования курсантов.

Результаты тестирования показали, что после 32 практических занятий в воде с контрольными упражнениями курсанты справились лучше. У курсантов были сформированы умения транспортировки, борьбы в воде, оказания помощи. Показатели плавательной подготовленности улучшились.

\section{Список литературы}

1. Алдошин А. В. Спорт в профессиональной физической подготовке сотрудников ОВД // Наука и практика. - 2014. - № 3 (60). - С. 126-128.

2. Башлакова Г. И., Гайдук С. А. К вопросу о прикладном плавании курсантов института пограничной службы Республики Беларусь / Совершенствование профессиональной и физической подготовки курсантов, слушателей образовательных организаций и сотрудников силовых ведомств : сборник статей ХХ Международной научно-практической конференции / отв. ред. С.М. Струганов. - Иркутск: Восточно-Сибирский институт МВД России, 2018. - С. 26-29.

3. Болотин А. Э., Дзюба А. С., Грачёв К. А. Педагогическая модель обучения прикладному плаванию курсантов образовательных организаций силовых структур с использованием методики замещения гидрогенных локомоций // Вестник Краснодарского университета МВД России. - 2017. - № 2 (36). - С. 227-231.

4. Весёлкина Т. Е., Крылов А. И. Обоснование содержания комплекса мероприятий повышения двигательной активности студентов на начальных этапах обучения в вузе // Учёные записки университета им. П.Ф. Лесгафта. - 2013. - № 10 (104). - С. 35-39.

5. Горобий А. Ю., Кондаков В. Л., Третьяков А. А. Двигательная активность в жизни студентов гуманитарного вуза. // Культура физическая и здоровье. - 2013. - № 2 (44). - С. 18-20.

6. Евграфов И. В., Кононов С. В., Радовицкая Е. В. Методики проведения самостоятельной оздоровительной физической тренировки студентов // Наука и культура России. - 2015. - Т. 1. C. 310-312.

7. Катыгин Ю. А., Умнов В. П., Чунаев А. А. Связь тревожности как свойства личности с некоторыми психофизиологическими характеристиками / Психофизиология учебной и спортивной деятельности. - Ленинград: Ленинградский государственный педагогический институт им. А.И. Герцена, 1975. - С. 46-51.

8. Кононов С. В. Развитие специальных физических качеств в процессе обучения прикладному плаванию студентов железнодорожных вузов : автореф. дис. ... канд. пед. наук : 13.00 .04 / Кононов Сергей Владимирович. - Санкт-Петербург, 2007. - 23 с.

9. Ткаченко А. И., Крысин М. В., Морев Д. Г., Кандабар А. Н. К вопросу осуществления межпредметных связей в образовательных организациях МВД России // Проблемы правоохранительной деятельности. - 2016. - № 4. - С. 83-88.

10. Третьяков А. А., Дрогомереикий В. В., Филатов М. С., Коренева М. С. Формирование умений оказания помощи на воде курсантами образовательных организаций МВД // Теория и практика физической культуры. - 2019. - № 8. - С. 78-81.

11. Чуриков А. И., Горелов А. А., Крылов А. И., Тарасов В. В. Профессиональная подготовка спецподразделений в прикладном плавании при ликвидации террористов при захвате различных судов и кораблей / Материалы итоговой научно-практической конференции академии физической культуры, посвящённой 300-летию Санкт-Петербурга. - Санкт-Петербург: Санкт-Петербургская государственная академия физической культуры им. П.Ф. Лесгафта, 2004. - С. 104-106. 


\section{References}

1. Aldoshin A. V. Sport v professional'noy fizicheskoy podgotovke sotrudnikov OVD // Nauka i praktika. - 2014. - № 3 (60). - S. 126-128.

2. Bashlakova G. I., Gayduk S. A. K voprosu o prikladnom plavanii kursantov instituta pogranichnoy sluzhby Respubliki Belarus' / Sovershenstvovaniye professional'noy i fizicheskoy podgotovki kursantov, slushateley obrazovatel'nykh organizatsiy i sotrudnikov silovykh vedomstv : sbornik statey XX Mezhdunarodnoy nauchno-prakticheskoy konferentsii / otv. red. S.M. Struganov. - Irkutsk: VostochnoSibirskiy institut MVD Rossii, 2018. - S. 26-29.

3. Bolotin A. E., Dzyuba A. S., Grachov K. A. Pedagogicheskaya model' obucheniya prikladnomu plavaniyu kursantov obrazovatel'nykh organizatsiy silovykh struktur $\mathrm{s}$ ispol'zovaniyem metodiki zameshcheniya gidrogennykh lokomotsiy // Vestnik Krasnodarskogo universiteta MVD Rossii. - 2017. № 2 (36). - S. 227-231.

4. Vesolkina T. Ye., Krylov A. I. Obosnovaniye soderzhaniya kompleksa meropriyatiy povysheniya dvigatel'noy aktivnosti studentov na nachal'nykh etapakh obucheniya v vuze // Uchonyye zapiski universiteta im. P.F. Lesgafta. - 2013. - № 10 (104). - S. 35-39.

5. Gorobiy A. Yu., Kondakov V. L., Tret'yakov A. A. Dvigatel'naya aktivnost' v zhizni studentov gumanitarnogo vuza. // Kul'tura fizicheskaya i zdorov’ye. - 2013. - № 2 (44). - S. 18-20.

6. Yevgrafov I. V., Kononov S. V., Radovitskaya Ye. V. Metodiki provedeniya samostoyatel'noy ozdorovitel'noy fizicheskoy trenirovki studentov // Nauka i kul'tura Rossii. - 2015. - T. 1. - S. 310-312.

7. Katygin Yu. A., Umnov V. P., Chunayev A. A. Svyaz trevozhnosti kak svoystva lichnosti s nekotorymi psikhofiziologicheskimi kharakteristikami / Psikhofiziologiya uchebnoy i sportivnoy deyatel'nosti. Leningrad: Leningradskiy gosudarstvennyy pedagogicheskiy institut im. A.I. Gertsena, 1975. - S. 46-51.

8. Kononov $S$. $V$. Razvitiye spetsial'nykh fizicheskikh kachestv v protsesse obucheniya prikladnomu plavaniyu studentov zheleznodorozhnykh vuzov : avtoref. dis. ... kand. ped. nauk : 13.00.04 / Kononov Sergey Vladimirovich. - Sankt-Peterburg, 2007. - 23 s.

9. Tkachenko A. I., Krysin M. V., Morev D. G., Kandabar A. N. K voprosu osushchestvleniya mezhpredmetnykh svyazey v obrazovatel'nykh organizatsiyakh MVD Rossii // Problemy pravookhranitel'noy deyatel'nosti. - 2016. - № 4. - S. 83-88.

10. Tret'yakov A. A., Drogomeretskiy V. V., Filatov M. S., Koreneva M. S. Formirovaniye umeniy okazaniya pomoshchi na vode kursantami obrazovatel'nykh organizatsiy MVD // Teoriya i praktika fizicheskoy kul'tury. - 2019. - № 8. - S. 78-81.

11. Churikov A. I., Gorelov A. A., Krylov A. I., Tarasov V. V. Professional'naya podgotovka spetspodrazdeleniy v prikladnom plavanii pri likvidatsii terroristov pri zakhvate razlichnykh sudov i korabley / Materialy itogovoy nauchno-prakticheskoy konferentsii akademii fizicheskoy kul'tury, posvyashchonnoy 300-letiyu Sankt-Peterburga. - Sankt-Peterburg: Sankt-Peterburgskaya gosudarstvennaya akademiya fizicheskoy kul'tury im. P.F. Lesgafta, 2004. - S. 104-106.

(с) Третьяков А.А., Ткаченко А.И., Дрогомерецкий В.В., 2019

Статья поступила в редакцию 25.07.2019 г. 